\title{
Cry of pain - autobiografisk hukommelse og selvmordsatferd
}

\author{
Ved Kenneth Pettersen og Nora Nord Rydningen
}

\begin{abstract}
Cry of pain-modellen er en anerkjent psykologisk modell for forståelse av selvmordsatferd (Williams, 2001). Modellen forklarer selvmordsatferd ut fra generelle psykologiske variabler, på tvers av eventuell underliggende psykopatologi. Vi vil her presentere generelle trekk og empiri som ligger til grunn for modellen. Vi vil spesielt fokusere på hvilken rolle overgeneralisert autobiografisk hukommelse spiller i utviklingen av selvmordsatferd.
\end{abstract}

Mark Williams (1997, 2001) forstår selvmordsfors $\varnothing \mathrm{k}$ og selvmord som dimensjonalt ulike utfall heller enn kvalitativt forskjellige, og argumenterer for å bruke begrepet selvmordsatferd som inkluderer både selvmordsfors $\varnothing \mathrm{k}$ med og uten d $\varnothing$ den til følge. Videre argumenterer han for at det er hensiktsmessig å forstå selvmordsatferd som en konsekvens av visse livsbetingelser heller enn i form av sin intensjon, og at selvmordsatferd utløses av en situasjon som består av tre komponenter:

1) Nederlag - opplevd nederlag, tap eller ydmykelse som gir et stort behov for å flykte fra situasjonen

2) Opplevelse av å være fanget - følelsen av at det ikke finnes noen vei ut av den uutholdelige situasjonen nå

3) Opplevelse av manglende redning følelse av håpløshet på grunn av antagelse om at tilstanden ikke vil bedre seg i fremtiden.

I hvilken grad de ulike komponentene er til stede, vil være avgjørende for hvor alvorlig selvmordsatferden er. Mens selvmord innebærer å faktisk unnslippe en uutholdelig livssituasjon, kan selvmordsfors $\varnothing \mathrm{k}$ sees på som fors $\varnothing \mathrm{k}$ på å etablere flukt- eller redningsmuligheter. En slik dimensjonal forståelse av selvmordsatferd innebærer at man ved å studere individer med tidligere selvmordsfors $\varnothing \mathrm{k}$ kan få kunnskap om risiko for selvmordsatferd generelt.

For å gi en pekepinn om hvordan forskning fra ulike felt møtes, beskriver Williams utviklingen av sin teori gjennom et fenomen hentet fra dyreverdenen. Det aktuelle fenomenet er arrested flight eller hindret flukt, et fenomen som evolusjonspsykologer opprinnelig studerte for å finne opphavet til depresjon (Gilbert \& Allan, 1998). Når fugler skal etablere sine territorier og møtes i utkanten av et territorium, kan de vise aggressiv atferd, og den ene fuglen vil tape mot den sterkere rivalen. Hvis den tapende fuglen er i stand til å fly av gårde for å finne et annet territorium, vil et slikt nederlag ha liten innvirkning på fuglen. Hvis den tapende fuglen derimot ikke kan flykte, produserer den høye motivasjonen til å komme seg unna, et helt annerledes utfall:

Atferden dens endres totalt. Dypt deprimert, ydmyket, med hengende vinger og bøyd nakke, blir den som lammet, selv om det er umulig å se noen fysiske skader. Fuglens motstand synes å være svekket, og $i$ noen tilfeller er den psykologiske virkningen så sterk at fuglen før eller siden ikke lenger vil klare seg. (Gilbert, 1999)

Eksemplet viser at nederlag i seg selv ikke er tilstrekkelig til å utløse en reaksjon. Kombinasjonen av nederlag og manglende fluktmuligheter er nødvendig for at reaksjonen skal oppstå. Videre har det blitt observert at dyr som viser en slik hjelpeløs reaksjon, kan komme seg igjen fra opplevelsen. Nærværet eller fraværet av redningsfaktorer vil bestemme hvor lenge reaksjonen kommer til å vare. Gilbert og Allan (1998) foreslår at nederlaget og innesperringen setter i gang en evolusjonær, primitiv biologisk prosess hos dyret, som det tar tid å komme over. Prosessen har en overlevelsesfunksjon ved at "taperens" underkastelse vanligvis fører til at "vinneren" avslutter angrepet, og at "vinneren” kan fortsette å være lederen, velge parringspartnere etc., uten å frykte å kontinuerlig bli utfordret av "taperen". Ut fra ovennevnte observasjoner har det blitt dannet hypoteser om at disse evolusjonære primitive prosessene også kan være til stede hos mennesker. Ydmykelser, nederlag eller avvisninger kan trigge slike "skjemaer" i situasjoner hvor flukt ikke er mulig (Gilbert \& Allan, 1998; Williams, Crane, Barnhofer \& Duggan, 2005b). Forskning på sammenhengen mellom nederlag og manglende fluktmuligheter hos mennesker, har gitt evidens for at begge variablene har en sterk sammenheng med klinisk depresjon (Gilbert \& Allan, 1998). Williams og hans kollegaer skiftet fokus fra depresjon per se til selvmordsatferd, og foreslår at risikoen for selvmordsatferd vil фke når man opplever seg fanget i en situasjon preget av nederlagsfølelse eller ydmykelse (Williams \& Pollock, 2001). Noen kan være mer sårbare for å oppleve nederlag, føle seg fanget og å overse mulig redningsfaktorer. Dette forventes å skje på tvers av ulike diagnosegrupper.

\section{Sensitivitet overfor nederlag/ydmykhetssignaler}

Det er god evidens for at opplevde negative hendelser er viktige i forhold til utvikling av depresjon og selvmordstanker (Williams, 2001). Williams postulerer at nederlagsopplevelser iverksetter gamle biologiske mønstre i hjernen, som kan påvirke sinnsstemningen og medf $\varnothing$ re en hypersensitivitet for nederlagssignaler. Dette kan bekrefte opplevelsen av å være en "taper". Forskning viser at mennesker har ulik følsomhet for stimuli som signaliserer et mulig eller faktisk nederlag. Man finner individuelle forskjeller i informasjonsprosessering (Williams, Barnhofer, Crane \& Beck, 2005a), i tillegg til at noen opplever flere faktiske nederlag (Brown, Harris \& Hepworth, 1995). Visse personer er altså mer sensitive i sin fortolkning av hendelser. Relativt n $\varnothing$ ytrale hendelser kan som resultat tolkes som ydmykende, som avvisning eller tegn på nederlag (Williams et al., 2005a).

Forskning på oppmerksomhetsskjevheter tydeliggj $\varnothing \mathrm{r}$ effekten av nederlagssensitivitet. Willams og Pollock (2001) refererer til studier på selektiv oppmerksomhet der en har funnet at stimuli som er spesielt viktig for en person (en aktuell bekymring), synes å dukke opp ofte.

For eksempel vil en person som tidligere har opplevd kraftig avvisning lettere kunne tolke det at en annen ikke hilser som å bli bevisst oversett, heller enn at personen kanskje gikk fordypet i egne tanker. Fenomenet kan forklares med at opplevde vanskelige livshendelser gir en disposisjon 
for å beskytte seg mot lignende hendelser i fremtiden (Williams \& Pollock, 2001). Williams understreker at denne oppmerksomheten initialt kan være frivillig, men at den etter hvert går over til å bli automatisert, ubevisst og ute av kontroll. Personen kan da bli bombardert av stimuli som bekrefter nederlagsfølelsen og/eller taperstatusen.

\section{Opplevelse av å være fanget}

Selvmordsfaren kan øke når personen i en nederlagssituasjon ikke finner en løsning på sine problemer, og samtidig har en sterk motivasjon til å unnslippe situasjonen. Dette fenomenet kalles entrapment, og defineres av Williams (2001) som "hva som helst som hindrer et dyr eller menneske i å slippe unna når det Ønsker å flykte (s. 149, vår oversettelse)". Ifølge data fra dyrestudier er det tilstanden av entrapment, og ikke selve nederlaget, som utgjør en fare (MacLean, 1990). På lignende måte argumenterer Williams (2001) for at hjelpeløsheten i en "entrapment-situasjon" er den grunnleggende dimensjonen ved selvmordsatferd.

Ikke alle som opplever alvorlige nederlag eller langvarig ydmykelse, vil reagere med å føle seg fanget i situasjonen eller i sine følelses- og tankem $\varnothing$ nstre. Forskning viser at opplevelsen av å føle seg fanget henger nøye sammen med evnen til effektiv problemløsning. Hos mennesker med psykiske lidelser finner man ofte klare problemløsningsvansker, og spesielt tydelig er dette for selvmordsnære individer (Williams et al., 2005b). Pollock og Williams $(2001,2004)$ har vist at personer med psykisk lidelse og tidligere selvmordsatferd presterer dårligere på oppgaver som måler mellommenneskelig problemløsningsevne, sammenlignet med personer med psykisk lidelse uten tidligere selvmordsatferd og en kontrollgruppe uten psykisk lidelse og tidligere selvmordsatferd. Problemløsningsvansker er videre funnet å kunne være uavhengige av sinnsstemning, noe som gir st $\varnothing$ tte til antagelsen om at svekket problemløsning kan være en del av de psykologiske prosessene som ligger til grunn for selvmordsatferd spesielt. Problemløsningsvansker viser seg ikke å være direkte prediktive for selvmordsatferd, men indirekte ved at de kan $\varnothing$ ke opplevelsen av å være fanget (Williams \& Pollock, 2001). Hvis man ikke kan definere et problem eller ikke har noen tanker om hvordan man kan løse det, kan følelsen av å være fanget være nærliggende.

\section{Overgeneralisert autobiografisk hukommelse}

Forskning på autobiografisk hukommelse, det vil si episodisk hukommelse for hendelser i eget liv, er viktig for å forstå de psykologiske mekanismene som ligger til grunn for problemløsningsvansker og selvmordsatferd. Det er god evidens for at gjenhenting av autobiografiske minner er hierarkisk organisert (Conway \& Pleydell-Pearce, 2000; Willams, Chan, Crane, Barnhofer, Eade \& Healy, 2006). Før man kan få tilgang til spesifikke minner, må man gå veien om semantiske begreper og generelle minner. Man kommer først til en generell beskrivelse av informasjonen som skal gjenhentes. Denne initiale beskrivelsen brukes til å søke for aktuelle kandidater i hukommelsen. Generelle minner fungerer altså som en slags innholdsfortegnelse og er nødvendig for å kunne navigere gjennom minnehierarkiet (Conway \& Pleydell-Pearce, 2000).

Overgeneralisert autobiografisk hukommelse kan forstås som vansker med å komme forbi innholdsfortegnelsen og til de minnene den refererer til. Dette medfører at en i stor grad mister tilgangen til spesifikke og detaljerte minner.

Forskning viser at individer uten tidligere selvmordsatferd, men som har ulike psykiske lidelser som depresjon (Goddard, Dritschel \& Burton, 1996), posttraumatisk stresslidelse (MacLeod, Williams \& Linehan, 1992), tvangslidelse (Wilhelm, McNally, Baer \& Florin, 1997) og schizofreni (Wood, Brewin \& McLeod, 2006), har en overgeneralisert autobiografisk hukommelse sammenlignet med individer uten psykisk lidelse. Videre tyder forskningen på at individer med psykisk lidelse og tidligere selvmordsatferd har en ytterligere overgeneralisert autobiografisk hukommelse sammenlignet med individer med psykisk lidelse uten tidligere selvmordsatferd (Pollock \& Williams, 2001; Leibetseder, Rohrer, Mackinger \& Fartacek, 2006). Forfatterne av denne artikkelen har gjennomf $\varnothing \mathrm{rt}$ den første studien som unders $\varnothing$ ker denne sammenhengen for individer med schizofreni (Pettersen \& Rydningen, 2006). I tråd med hypotesen produserte individene med schizofreni og tidligere selvmordsatferd signifikant færre spesifikke minner sammenlignet med individene med schizofreni uten tidligere selvmordsatferd. I analyser der vi kontrollerte for aktuell depresjon, håpløshet, symptomer, suicidalitet og demografiske variabler, ble det ikke vist effekt av tredjevariabler eller interaksjonseffekter på sammenhengen mellom overgeneralisert autobiografisk hukommelse og tidligere selvmordsatferd. Studien gir st $\varnothing$ tte til at overgeneralisert autobiografisk hukommelse er en psykologisk prosess som kan gi en sårbarhet for selvmordsatferd ut over det som kan forklares av psykisk lidelse.

Årsaker til overgeneralisert autobiografisk hukommelse

Man vet lite om årsakene til overgeneralisert autobiografisk hukommelse, men Williams (2006) foreslår at det er 3 prosesser, som enten alene eller i kombinasjon, kan gi en overgeneralisert autobiografisk hukommelse. For det første er det funnet en assosiasjon mellom overgeneralisert autobiografisk hukommelse og negative livshendelser. Gjenhenting av spesifikke detaljer kan være koblet med sterk aversiv affekt, og det er evidens for at overgeneralisert autobiografisk hukommelse kan utvikles som en mekanisme for å regulere negativ affekt (Raes, Hermans, Williams \& Eelen, 2006). Overgeneralisert hukommelse kan i lys av dette forstås å ha en adaptiv funksjon, ved at personen kan beskytte seg mot traumatiske negative minner (Williams $\&$ Pollock, 2001). For det andre har "ruminering", det vil si gjentatt grubling over viktige selvrelevante temaer, vist seg å forstyrre gjenhentingen av spesifikke minner. Overlapp mellom det en person skal fors $\varnothing$ ke å gjenhente og personens holdninger og bekymringer, kan $\varnothing \mathrm{ke}$ sannsynligheten for at grubling igangsettes. Det er vist at grubling skjer på et generelt nivå, noe som forstyrrer tilgangen til spesifikke minner (Williams, 2006). 


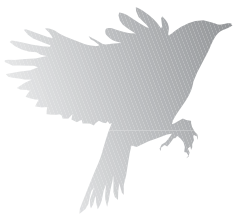

Den tredje prosessen er ineffektive eksekutive funksjoner, som kan føre til at man "henger seg opp" på det generelle nivået i minnehierarkiet. Fenomenet er kjent som mnemonic interlock (Williams, 2001). Grunnet sirkulære søkeprosesser på det generelle nivået mister hukommelsessystemet sin evne til å gjenhente spesifikke minner når det er påkrevd. Ineffektive eksekutive funksjoner bidrar til at man ikke er i stand til å avbryte den sirkulære søkeprosessen (Conway \& Pleydell-

Pearce, 2000; Raes et al., 2006).

\section{Implikasjoner av overgeneralisert autobiografisk hukommelse}

Hvilke implikasjoner kan overgeneralisert autobiografisk hukommelse ha for utviklingen av selvmordsatferd? Funn tyder på at overgeneralisert hukommelse kan bidra til å forlenge episoder med affektiv lidelse (Peeters, Wessel, Merckelbach \& Boontion, 2003). Mer spesifikt finner man at liten tilgang på spesifikke minner er vist å redusere et individs evne til å forestille seg en spesifikk fremtid (Williams et al., 1996). Dette kan øke håpløshetsfølelsen og opplevelsen av manglende redningsfaktorer. Det er videre påvist en tydelig sammenheng mellom overgeneralisert autobiografisk hukommelse og svekket evne til å løse mellommenneskelig problemer (Pollock \& Williams, 2001; Goddard et al., 1996;

Williams et al., 2006).

Problemløsningsevnen svekkes ved at personen i mindre grad har tilgang til konkret materiale fra eget minne, som nye løsninger kan formes ut fra. Ved å kunne gjenhente spesifikke hendelser, positive og negative, vil en med st $\varnothing$ rre sannsynlighet klare å generere alternative problemløsningsstrategier, ettersom en da har rikere tilgang på tidligere vellykkete $1 \varnothing s-$ ningsstrategier (Williams, 2001). Gjenhentingsvansker kan derimot blokkere tilgangen til effektive løsninger. Overgeneralisert autobiografisk hukommelse ser dermed ut til å være en viktig variabel for utviklingen av selvmordsatferd, gjennom å $\varnothing$ ke sannsynligheten for å føle seg fanget, og som vi skal se nærmere på, gjennom å $\varnothing$ ke sannsynligheten for å oppleve at det i fremtiden ikke finnes noen redning ut av problemene.

\section{Opplevelse av manglende redning}

Cry of pain-modellen postulerer at verken nederlag eller manglende fluktmuligheter vil være nok til å utløse selvmordatferd. Det er også vesentlig hvordan personen vurderer muligheten for at situasjonen vil kunne endre seg med tiden, muligheten for å bli "reddet". I forhold til arrested flight-modellen (Gilbert \& Allan, 1998) blir dette parallelt med fuglens mulighet til å komme seg til hektene igjen, noe som vil være bestemmende for hvor lenge hjelpeløshets/håpløshetsreaksjonen vil vare. Mangelende håp for fremtiden spiller en sentral rolle i utviklingen av selvmordsatferd. Flere studier rapporterer at håpløshet er mer relatert til selvmordsatferd enn depresjon (for eksempel Beck, Kovacs \& Weissman, 1975). Det ser ut til at mennesker kan holde ut depresjon så lenge de er i stand til å tenke at fremtiden blir bedre, men hvis de opplever håpløshet, фker risikoen for selvmordsatferd.

Evnen til å forestille seg en mulig endring i fremtiden forutsetter såkalt prospektiv kognisjon. Forskere på dette feltet har studert personers vurdering av sjansen for at ulike positive og negative hendelser vil skje i fremtiden. Empirien tyder på at håpløsheten hos personer med selvmordsatferd ikke innebærer at de ser for seg flere fremtidige negative hendelser, men at de har vansker med å danne seg bilder av fremtidige positive hendelser

(MacLeod, Rose \& Williams, 1993).

I lys av Cry of pain-modellen kan dette omformuleres til at personene har vansker med å se for seg fremtidige redningsfaktorer. Macleod et al. (1993) fant en klar sammenheng mellom vansker med å se for seg positive hendelser på lang sikt og vansker med å se for seg positive hendelser de første døgnene. I den samme studien fant de videre at overgeneraliserte minner har en innvirkning på evnen til å se for seg konkrete hendelser i fremtiden. Informantene med tidligere selvmordsatferd var både mindre spesifikke om fortid og fremtid, og opplevde større håpløshet med tanke på fremtiden. Williams (2001) argumenterer for at overgeneralisert autobiografisk hukommelse kan medføre at håpløsheten utvikler seg uten hindringer, fordi personen ikke klarer å se for seg spesifikke redningsfaktorer. Personen klarer ikke å stoppe eller bremse selvmordstankene, og selvmordsfors $\varnothing \mathrm{k}$ oppleves som eneste mulighet ut av den uutholdelige tilstanden.

\section{Trekk eller tilstand?}

De fleste studier av psykologiske prosesser ved selvmordsatferd er foretatt kort tid etter et selvmordsfors $\varnothing \mathrm{k}$ (Williams et al., 2005a). Det er derfor vanskelig å avgjøre hvorvidt svekkelsene man observerer er tilstandsavhengige, det vil si forårsaket av den vanskelige psykiske tilstanden personene befinner seg, eller trekkbaserte. Den foreliggende forskningen indikerer at selv om problemløsningsvansker og håpløshetsf $\varnothing$ lelse $\varnothing$ ker i en suicidal krise, og reduseres i etterkant, har individer med en historie med selvmordsatferd signifikant st $\varnothing$ rre problemer med problemløsning og håpløshet i perioder hvor de ikke er i krise. Dette indikerer at problemløsningsevne og håpløshet har både tilstands- og trekkegenskaper (Pollock og Williams, 2004). Da det er god evidens for at overgeneralisert autobiografisk hukommelse kan bidra til problemløsningsvansker (Pollock \& Williams, 2001) og фkt håpløshetsfølelse (Williams et al., 1996), gir de ovennevnte studiene indirekte st $\varnothing$ tte til at overgeneralisert autobiografisk hukommelse er en trekkbasert psykologisk variabel som kan bidra til sårbarhet for selvmordsatferd uavhengig av psykisk lidelse.

\section{Avslutning}

Vi har i denne artikkelen gitt en innføring i Cry of pain-modellen, en psykologisk modell som fors $\varnothing$ ker å binde sammen ulike felt av selvmordsforskningen. $\mathrm{Vi}$ har vist at sosiale signaler kan igangsette psykologiske og biologiske prosesser $\mathrm{i}$ individet, noe som medfører at informasjonsprosesseringen kan bli forutinntatt og skjev. Mer spesifikt har vi fokusert på forskning på overgeneralisert autobiografisk hukommelse som ved å bidra til å svekke problemløsningsevnen og $\varnothing \mathrm{ke}$ håpløshetsfølelsen, ser ut til å være en viktig faktor i utviklingen av selvmordsatferd. Resultatet kan bli en ond sirkel hvor individet føler seg fanget i en uutholdelig smerte og hvor selvmordsatferd fremstår som eneste utvei. 


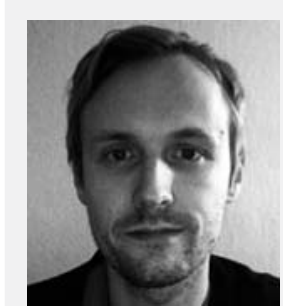

Kenneth Pettersen er psykolog ved Psykiatrisk akuttavdeling, Lovisenberg Diakonale Sykehus.

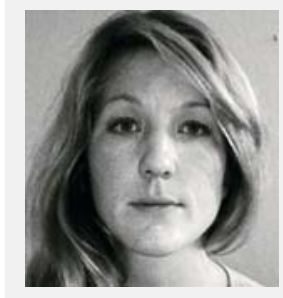

Nora Nord

Rydningen er psykolog ved Incognito Klinikk i Oslo.

\section{Referanser}

Beck, A. T., Kovacs, M. \& Weissman, A. (1975) Hopelessness and suicidal behaviour: Overview. Journal of the American Medical Association, 234 (11), 1146-1149.

Brown, G. W., Harris, T. O. \& Hepworth, C. (1995) Loss, humiliation, and entrapment among women developing depression: A patient and non-patient comparison. Psychological Medicine, 25, 7-21.

Conway, M. A. \& Pleydell-Pearce, C. W. (2000). The construction of autobiographical memories in the self-memory system. Psychological review, $107,261-288$

Gilbert, P. (1999). Human nature and suffering. Hove \& London: Lawrence Erlbaum Associates.

Gilbert, P. \& Allan, S. (1998). The role of defeat and entrapment (arrested flight) in depression: A exploration of an evolutionary view. Psychological Medicine, 28, 585-598.

Goddard, L., Dritschel, B. \& Burton, A. (1996). Role of autobiographical memory in social problem solving and depression. Journal of Abnormal Psychology, 105, 609-616.

Leibetseder, M. M., Rohrer, R. R., Mackinger, H. F. \& Fartacek, R. R. (2006). Suicide attempts: Patients with and without an affective disorder show impaired autobiographical memory specificity. Cognition and Emotion, 20 (3/4), 516-526.

MacLean, P. D. (1990). The triune brain in evolution. New York: Plenum Press.

MacLeod, A. K., Rose, G. S. \& Williams, J. M. G. (1993). Components of hopelessness about the future in parasuicide. Cognitive Therapy and Research, 17, 441-455.

MacLeod, A. K., Williams, J. M. G. \& Linehan, M. M. (1992). New developments in the understanding and treatment of suicidal behaviour. Behavioural Psychotherapy, 20, 193-218.

Peeters, F., Wessel, I., Merckelbach, H. \& BoonVermeeren, M. (2003). Autobiographical memory specificity and the course of major depressive disorder. Comprehensive Psychiatry, 43, 344-350.
Pettersen, K. \& Rydningen, N. N. (2006). Autobiografisk hukommelse og selvmordsatferd hos pasienter med schizofreni. Hovedoppgave i psykologi, Psykologisk Institutt, Universitetet i Oslo.

Pollock, L. R. \& Williams, J. M. G. (2001). Effective problem solving in suicide attempters depends on specific autobiographical recall. Suicide and Life-Threatening Behaviour, 31 (4), 386-396.

Pollock, L. R. \& Williams, J. M. G. (2004).

Problem-solving in suicide attempters.

Psychological Medicine, 34, 163-167.

Raes, F., Hermans, D., Williams, J. M. G. \& Eelen, P. (2006). Reduced autobiographical memory specificity and affect regulation. Cognition and Emotion, 20 (3/4), 402-429.

Wilhelm, S., McNally, R. J., Baer, L. \& Florin, I. (1997). Autobiographical memory in obsessivecompulsive disorder. British Journal of Clinical Psychology, 36, 21-32.

Williams, J. M. G. (1997). Cry of pain: Understanding suicide and self-harm. Harmondsworth Penguin

Williams, J. M. G. (2001). Suicide and attempted suicide: Understanding the cry of pain. London: Penguin.

Williams, J. M. G. (2006). Capture and rumination, functional avoidance, and executive control (CaRFAX): Three processes that underlie overgeneral memory. Cognition and emotion, 20 (3/4), 548-568.

Williams, J. M. G., Barnhofer, T., Crane, C. \& Beck, A. T. (2005a). Problem solving deteriorates following mood challenge in formerly depressed patients with a history of suicidal ideation. Journal of Abnormal Psychology, 114 (3), 421-431.

Williams, J. M. G., Chan, S., Crane, C., Barnhofer T., Eade, J. \& Healy, H. (2006) Retrieval of autobiographical memories: The mechanisms and consequences of truncated search. Cognition and Emotion, 20 (3-4), 351-382.

Williams, J. M. G., Crane, C., Barnhofer, T., \& Duggan, D. (2005b). Psychology and suicidal behaviour: Elaborating the entrapment model. I: K. Hawton (red.). Prevention and treatment of suicidal behaviour: From science to practice. Oxford: Oxford University Press.

Williams, J. M. G., Ellis, N. C., Tyers, C., Healy, H., Rose, G. \& MacLeod, A. K. (1996). The specificity of autobiographical memory and imageability of the future. Memory and Cognition, $24,116-125$.

Williams, J. M. G. \& Pollock, L. R. (2001).

Psychological aspects of the suicidal process. I: K. van Heeringen (red.). Understanding suicidal behaviour: The suicidal process approach to research, treatment and prevention. Chichester: John Willy.

Wood, N., Brewin, C. R. \& McLeod, H. J. (2006) Autobiographical memory deficits in

schizophrenia. Cognition and Emotion, 20 (3-4), 536-547. 